\title{
The Varying Fine Structure and Chemical Composition of Human Hair
}

\author{
A. Halat, ${ }^{*}$ A. Calabro, ${ }^{* *}$ D. Becker,** J. Morales** \\ * Bergen County Technical High School, Law and Justice Department, 504 Rt. 46 West, Teterboro, \\ NJ 07608 \\ ** Bergen County Academies, Microscopy Laboratory, 200 Hackensack Avenue, Hackensack, NJ \\ 07601 \\ *** City College of New York, Electron Microscopy Facility, 160 Convent Avenue, New York, NY \\ 10031
}

In criminalistics, hair is more often used to exclude a suspect rather than to brand one. However, given the circumstances of a case, such samples may prove to be valid evidence. Human hair samples are generally divided into three main categories: Mongoloid, Caucasian and Negroid. Another constant regarding hair is the ease with which it is altered by outside influences, which could potentially be of more use in forensic science. To determine differences in structure and chemical composition between treated (dyed) and untreated hair, and its significance in forensic science, hair samples were studied using a scanning electron microscope (SEM) with an energy dispersive x-ray spectrometry (EDS) detector and a focused ion beam (FIB).

Aside from previously known differences in size and gross anatomy, no significant fine structural or chemical differences were found among hair samples from different races (results not shown). Treated hair, on the other hand, showed some striking differences in structure and chemical composition. Treated hair showed striations, as well as particulate material deposits (Fig.1b). Charging was more pronounced on treated, than on untreated hair (Figs.1a \& 1b). Untreated hair did not show any visible striations or any particulate material deposition. The EDS spectrum of treated hair showed traces of silicon and calcium (Fig.2b), which were not present on untreated hair samples (Fig.2a). In addition to morphological and chemical microanalysis, the focused ion beam was used to further characterize treated and untreated hair specimens. Preliminary FIB results show severe curtaining and re-deposition artifacts resulting from the milling process (Fig.1c ). Currently we are experimenting with different currents to optimize the milling process on hairs. Chemical differences and fine structural features obtained by a combination of SEM imaging, milling and EDS analysis could potentially be used to find matches between hairs left at a crime scene and a suspect. 

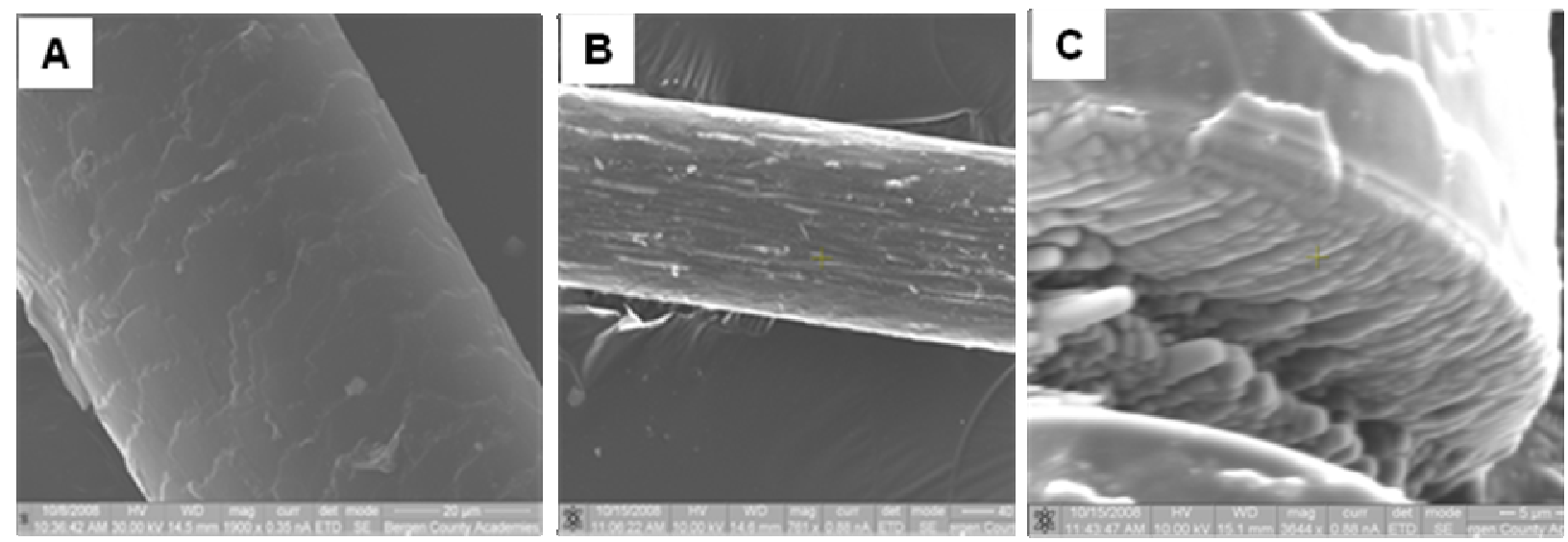

FIG. 1. Scanning electron micrographs of untreated (A) dye-treated (B) and FIB milled human hair. Note striations and increased charging on treated hair as compared to the untreated sample.
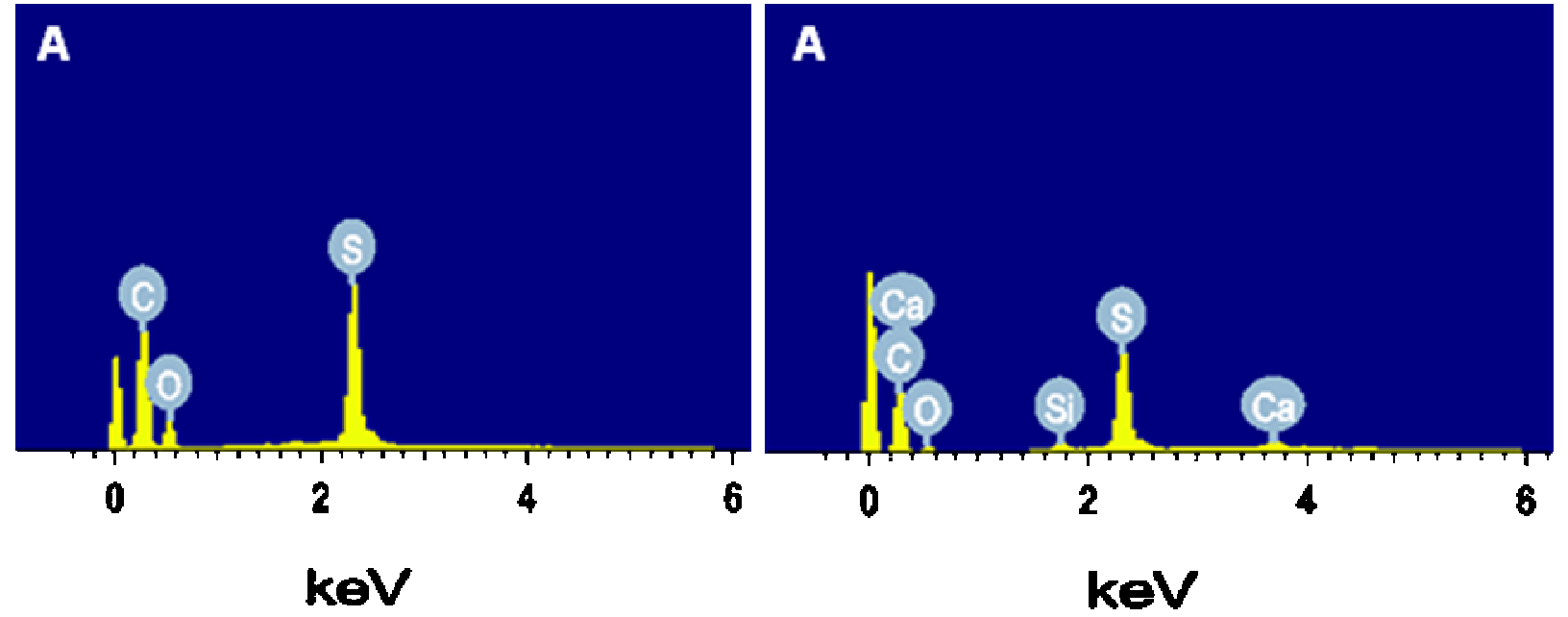

FIG. 2. EDS spectra of untreated (A) and treated (B) human hair. Note the presence of Si and Ca in the treated hair. 